\title{
Discussion on the Status and Supervision of Industrial Energy Conservation and Emission Reduction in Gansu Province
}

\author{
Rili Yang, Guangsheng Zhang, Wanying Jia \\ School of Energy Engineering, Long-Dong University, Qing'yang, Gan'Su, 745000,
}

\begin{abstract}
Through investigations on some key high energy-consuming enterprises (metallurgy, building materials, coal chemical industry) in Gansu Province, it was found that various industries had different understandings on the work, which mainly focused on some aspects on enterprise capacity development, the advanced technology, the relation between inputs and the output. In addition, especially government supervision had a great importance on the whole work, such as the complete laws and timely implementation of existing problems. In view of above all, this paper put forwards to strengthen energy conservation and emission reduction from the aspects of the supervision mechanism construction and the supervision system, which had a certain significance for the guidance of energy conservation and emission reduction.
\end{abstract}

\section{Introductions}

According to the notice of the 'Key Work Plan for Industrial Energy Conservation Supervision in 2019', the notice requires the supervisory departments to actively promote the energy consumption supervision actions of key high energy-consuming industries in Gansu Province. Based on energy-saving standards, it is suggested to resolutely do a good job of Energy saving supervision and other work. The work plan proposes that a series of highenergy-consumption special supervision work should be carried out on some high-energy-consuming industries.

Through the investigation on the special monitoring work, it was found that there were obvious differences in the development of energy conservation and emission reduction in enterprises. Some enterprises had truly recognized the importance and regarded energy conservation work as the economic growth point, which have complete and reasonable energy conservation organizations, actively advanced technology, regularly conducting energy-saving publicity and some energysaving training to improve employees' energy-saving awareness and technical level.

However, in the process of monitoring, there were some enterprises' energy-conserving work that have not been recognized. They set up organizations only to set targets in response to the requirements, which resulted in the fact that the energy consumption data we collected was not true [1], accurate and complete, without real implementation. Some enterprises lag behind in energyconserving equipment and used low utilization rates, which could not meet emission requirements ${ }^{[2]}$. These existing conditions made the supervision department's supervision of enterprises fail to reflect the actual situation of energy-saving enterprises, which seriously affected the supervision, and the implementation of China's energy-conserving emission reduction strategy, and it was beneficial to conducive in the long-term development of enterprises. All in all, there were still a series of deficiencies and urgent problems that need to be addressed in the supervision of energy-consuming enterprises.

\section{Some thoughts about industrial energy conservation supervision construction}

\subsection{Improve the supervision system, increase supervision and form a long-term mechanism}

Firstly, the construction of energy-saving supervision mechanisms at the provincial, city, and county levels was strengthened. And they were conducted to increase business guidance through cross-regional business exchanges, joint law enforcements, mutual assistance, and improve energy conservation supervision mechanism. Which was beneficial to play the role of grass-roots supervision institutions, and promote the balanced development of energy conservation supervision in different regions ${ }^{[3]}$.

Secondly, for the supervision staff it was necessary to Strengthen the law consciousness, actively learn some relative legislations and improve their own business level. Meanwhile, it is essential to supplement different links and crystallize responsibility, which is useful to form a reasonable supervision assessment method that can simply the monitoring detail and make the site data quantization.

Finally, it was necessary to strengthen supervision and form a long-term mechanism. The detailed work was concentrated on energy-consuming equipment and methods, make sure that they can meet the requirements. It is necessary to clarify the main responsibility of the

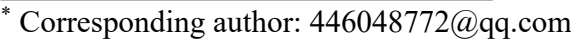


enterprise, for example, timely to issue a list of rectifications for the problems found in the monitoring process, and specify the time limit for rectification. For enterprises that have not repeatedly taught, they can take corresponding compulsory measures in accordance with the law.

Supervision work should not be carried out in a hurry, nor should it be tried and tested. It is necessary to form a long-term mechanism and regularly carry out supervision. Each monitoring work should highlight the key points, implement special rectification activities on common problems, and gradually achieve breakthroughs in problems. The most important thing is that supervision must be open and transparent. Not only procedures must be open and legal, but also penalties must be made public.

\subsection{Strengthen the supervision basic work and improve the Informaionization level}

Supervision agencies at all levels conduct thorough investigations and daily ordinary monitoring of key energy-saving enterprises in the province ${ }^{[4]}$. For the annual energy consumption ability is more than 5000t/a, it is essential to investigate energy utilization, the establishment of an energy management system and posts, the appointment of the person in charge of energy management of key energy-using enterprises, which should be monitored detailly.

The implementation of energy measurement, energy consumption statistics and energy utilization status reporting system for key energy-consuming enterprises, must be strictly monitored. It is planned to initiate the construction of a smart data monitoring platform for industrial energy conservation, which is conductive to encourage localities to strengthen the online information monitoring methods, explore online verification of energy efficiency with the help of energy equipment. Based on the online energy conservation monitoring results and electronic files of key energy equipment for key enterprises, it is important to enhance energy conservation monitoring, improve the level of energy efficiency and promote more efficient and accurate energy conservation monitoring

\subsection{Strengthen the energy-saving management of energy-consuming units and energy-saving equipment}

In accordance with the principle of combining territorial management and hierarchical management, it is useful to cooperate with the state to do the work on evaluating the target responsibilities of key energy-using enterprises ${ }^{[5]}$, the provinces and municipalities where had completed the responsibility evaluations. The results of the assessment must be announced in a timely manner. Combined with the national energy efficiency labeling, energy-saving and low-carbon product certification system, it is suggested to strengthen the supervision and management of energy efficiency and implement

In particularly, the main jobs are focused on energysaving review, supervision of high-energy-consuming special equipment, and building a three-levels supervision system of energy conservation and environmental protection. It is conductive to supervise and guide key energy-consuming units to build an energy system, establish an energy monitoring. Based on the local relative laws and regulations, it is implemented to organize the energy performance evaluations and conduct to some voluntary activity.

\section{Measurements about how to improve energy conservation monitoring}

\subsection{Establish green, digital and information- based energy supervision system}

Combined with the advanced information technology, it is good for making full use of the development of informatization and big data to improve the measurement, which is convenient to collect monitoring statistics and for pre-warning actions ${ }^{[6-7]}$. We will improve the energy measurement system and consumption statistics indicator system, improve the enterprise direct reporting system, increase the auditing and enforcement of statistical data, strengthen the quality management of statistical data, and ensure the basic convergence of statistical data.

Based on the established and improved an online monitoring system for energy consumption and an automatic online monitoring system for pollution sources, real-time monitoring and reporting of energy consumption of key energy-consuming unit is becoming easy and makes difference, which is enhanced units' selfmonitoring of pollutant emissions and ensures effective transmission rates of effective automatic monitoring of pollution sources. The enterprise should monitor itself.

\subsection{Use new energy-saving equipment, focusing on re-innovation of the introduction, digestion of new technologies for energy conservation and emission reduction.}

Adopt advanced and applicable new technologies for energy conservation and emission reduction. According to local conditions, the owner is recommended to use new energy consuming technologies, new processes, new equipment, and new technical solutions. Especially for the high energy consumption and heavy pollution industries, it is suggested to pay attention to adopt advanced indicators and processes and equipment during the whole design period. Most large design units can actively research and develop technology with independent intellectual property rights to meet national and project needs, and strive to reduce investment costs for enterprises to adopt new technologies. Actively innovate, organize research, and develop new technologies to serve energy conservation and emission reduction.

\subsection{Strengthen the liaison between supervision departments and enterprises}

Monitoring is a 'two-way' action. The supervisory authority should not always in a dominated role. The 
supervision department must not only strengthen communication with the enterprise, but also cooperate with each other on the supervision work between the supervision staffs. Both the supervision department and the enterprise should conduct in-depth research and discussion on the overall and details of the supervision work to ensure the smooth development of various tasks and achieve the role of improving resource utilization efficiency, saving energy and reducing emissions, and alleviating energy tensions, which all measurements was put forward to find the existing problems in the process of energy conservation monitoring.

The supervisory staff should make full use of their professional knowledge and skills to provide relevant training to relevant personnel of the enterprise, teach them methods and techniques to solve energy conservation problems, and help enterprises reduce energy consumption and achieve environmental protection. Ask for a plan. At the same time, companies should also actively share good energy-saving practices with supervisory agencies. Supervision work is not only an inspection act, but also a process of monitoring both parties to learn and progress together to achieve common progress.

\subsection{Constitute Energy conservation supervision system}

In accordance with the principle of combining enterprises and local management and supervision units, a system suitable for industrial energy conservation supervision is formulated. First of all, enterprises adopt advanced and applicable new energy-saving and emission-reduction technologies, use current information technology and the development of big data, improve green digitalization, and information-based energy-saving monitoring network systems to monitor energy-saving and emissionreduction measurement in real time, and use digitalization for statistics, monitoring, and early warning. At the same time, the company's networked direct reporting system is used to report to the higher-level energy conservation monitoring agency at a fixed time. The higher-level energy conservation monitoring agency reports real-time monitoring and reporting of energy consumption of key energy-consuming units, strengthens self-monitoring of pollutant emissions and environmental information disclosure to ensure effective the pollution source automatically monitors the effective data transmission rate. The detailing processes as fig 1 follows.

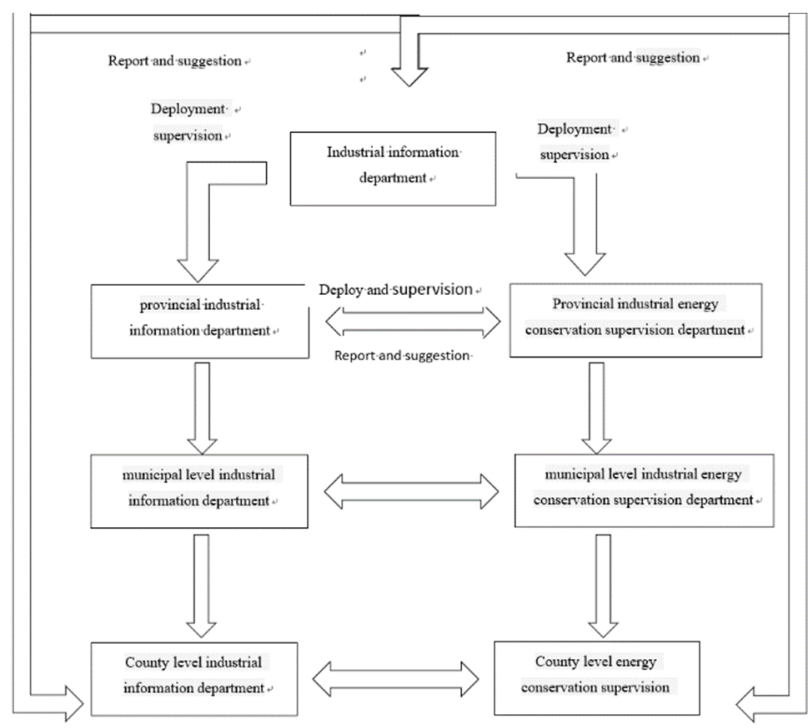

Fig. 1. The three level energy conservation supervision system

In response to problems found in the process of energy conservation monitoring, higher-level energy conservation monitoring agencies should provide timely feedback, and when necessary, dispatch monitoring staff, make full use of their professional knowledge and skills, provide corresponding training to relevant personnel of the enterprise, and teach them how to solve energy conservation problems, Tips for companies to advise on how to reduce energy consumption and meet environmental protection requirements. For some key monitoring enterprises, it is necessary to take target responsibility evaluation and assessment, and carry out statistical data, effect evaluation, assessment and evaluation, and key rectification measures every quarter. In the process of supervision and evaluation, the main responsibility of the enterprise shall be clearly defined. For problems found during the supervision, a specific rectification list shall be issued for the enterprise, and the time limit for rectification shall be specified. For some enterprises that have not completed the rectification tasks in accordance with the regulations, administrative penalties shall be imposed in accordance with the law. For those enterprises that have not repeatedly taught, they may adopt corresponding compulsory measures in accordance with the law, and in the long run, form a longterm mechanism to ensure the effective development of energy conservation supervision.

The contradiction between China 's economic and social construction and energy is becoming more and more serious. it is essential to build a resource-saving and environment-friendly society for sustainable economic and social development of our country. In particularly, more attention must be played to improve energy-saving supervision and upgrade energy-saving supervision technology. What is more, it is necessary to continuously innovate the relative laws and regulations about the supervision and emission standards. In the long run, it is useful to build a long-term monitoring mechanism to lay a foundation for China's sustainable economic and social development. 


\section{Acknowledgement}

This research paper was supported by Gansu Provincial Industrial Green Low Carbon Transformation and Upgrade Project in 2019 (GGLD-2019-038).

\section{References}

1. Zhang Ruiping .Policy evaluation and legal system guarantee for energy conservation and emissions reduction in Gansu province[J]. Journal of Lanzhou university of arts and science,2017 vol33,

2. Gao Zixiang. Research on the difference of energysaving target of provincial government in china[D]. Huaqiao university,2016

3. Wei Guo, Yang Min. Contemn erasures of building monitoring and evaluation system of energy saving and emission reduction[J]. Journal of Huangshi institute of technology,2008,vol 24

4. Zhang Hongliang, Shu Haiwen. A Comprehensive Evaluation on Energy, Economic and Environmental Performance of the Trombe Wall during the Heating Season[J]. Journal of Thermal Science,2019

5. Guo Pengxin, Li Hongqiang, He Changjie, Zheng Yingfa, Li Shuisheng. Research on Landscape Energy-Saving Integrated Water Curtain System[J]. Journal of Thermal Science,2019

6. David Boto-García, Alessandro Bucciol. Climate change: Personal responsibility and energy saving[J]. Ecological Economics, 2019

7. Sivanand Somasundaram; Alex Chong; Zhang Wei. Energy saving potential of low-e coating based retrofit double glazing for tropical climate[J]. Energy \& Buildings, 2019 